declared, Valentina lannizzotto: None declared, Elena Pipi: None declared, Joana Campos: None declared, Saba Nayar: None declared, Francesco Ciccia Grant/research support from: CELGENE, PFIZER, Consultant for: UCB, NOVARTIS, CELGENE, PFIZER, LILLY, Paid instructor for: UCB, NOVARTIS, CELGENE, PFIZER, LILLY, JANSSEN, Speakers bureau: UCB, NOVARTIS, CELGENE, PFIZER, LILLY, JANSSEN, MSD, ROCHE, AMGEN, Francesca Barone Grant/research support from: GlaxoSmithKline, Roche, UCB Pharma, Actelion, ONO Pharmaceutical, Consultant for: GlaxoSmithKline, Roche, Actelion, ONO Pharmaceutical, Guido Valesini: None declared, cristiano alessandri: None declared

DOI: 10.1136/annrheumdis-2019-eular.5901

\section{SAT0005 DETECTION OF HIGHLY EXPANDED T CELL CLONES IN THE PERIPHERAL BLOOD OF AT RISK INDIVIDUALS FOR RHEUMATOID ARTHRITIS BEFORE THE CLINICAL ONSET OF THE DISEASE}

Céline Lamacchia ${ }^{1}$, Zuleika Calderin ${ }^{1}$, Delphine Courvoisier ${ }^{1}$, Denis Mongin ${ }^{1}$, Stéphane Buhler ${ }^{1}$, Gaby Palmer ${ }^{2}$, Olivia Studer ${ }^{1}$, Cem Gabay ${ }^{1}$, Jean Villard ${ }^{1}$, Axel Finckh ${ }^{1} .{ }^{1}$ University Hospitals of Geneva, Geneva, Switzerland, ${ }^{2}$ University of Geneva School of Medicine, Geneva, Switzerland

Background: Rheumatoid arthritis (RA) is an autoimmune disease with unknown etiopathogenesis. Systemic autoimmunity precedes clinical disease onset, and current evidence suggests that the immune onset of RA takes place outside of the joints several years before clinical manifestations. Expanded $T$ cell clones can be found in the synovial tissue of established RA patients. The mechanisms by which systemic immune abnormalities progress to joint-specific autoimmunity are not yet understood.

Objectives: To examine if expanded $T$ cell clone signatures can be detected in the peripheral blood before the development of clinical RA. Methods: Next-generation sequencing of the T Cell Receptor $\beta$ (TCR $\beta$ ) CDR3 repertoire was performed on genomic DNA isolated from blood samples of individuals genetically at risk for RA, namely first-degree relatives of RA patients (RAFDR) at different pre-clinical phases of disease development (SCREEN-RA cohort), and of matched RA patients used as a control group (SCQM cohort). All individuals were matched for age and sex, and categorized into four groups ( $n=20 /$ group): Group 1: "healthy" asymptomatic RA-FDR without autoantibodies or symptoms associated with possible RA. Group 2: Asymptomatic RA-FDR with evidence of 'systemic autoimmunity associated with RA' defined by high levels of anti-citrullinated peptide antibodies (ACPA; $3 x \geq U L N$ ). Group 3: RA-FDR having presented undifferentiated arthritis $(n=8)$ or having developed classifiable $R A$ after inclusion $(n=12)$. Group 4: patients with established RA of less than 3 years duration. T cell clones were identified by their unique TCR $\beta$ CDR3 sequence. Clones with a frequency over $0.5 \%$ were considered to be highly expanded clones (HEC). Both absolute number and frequency of productive $\mathrm{T}$ cell clones was compared between the 4 groups using mixed effect regression models to account for matching.

Results: As expected, the large majority of clones in the peripheral blood were detected at very low frequency $(<0.1 \%)$ in all groups (Figure $1 \mathrm{~A}$ ). Interestingly, expanded clones $(>0.1 \%$ of total TCR analysed) tended to occur more frequently in later preclinical phases and established disease. A significant difference among groups was observed for highly expanded clones (HEC) $(p=0.001)$. Specifically, the absolute number of HEC was significantly higher in RA patients (group 4; mean 4.65, $\mathrm{p}=0.003$ ) and tended to be higher in symptomatic RA-FDR (group 3; mean 3.4, $\mathrm{p}=0.07$ ) compared to "healthy" RA-FDR (group 1; mean 1.55) (Figure 1B). A trend towards a higher frequency of the top 50 expanded clones was also observed in symptomatic RA-FDR (group 3; mean $0.17 \%$ ) compared to "healthy" RA-FDR (group 1; mean $0.11 \%$ ). At risk individuals defined by the presence of high ACPA levels (group 2) did not differ from "healthy" RA-FDR in terms of absolute number and frequency of clones.

Conclusion: For the first time, highly expanded $\mathrm{T}$ cell clones were detected in the peripheral blood of at risk individuals before the clinical onset of RA, in particular in the later pre-clinical phases of RA development. Tracking these dominant $\mathrm{T}$ cell clones in longitudinal analyses and elucidating their role might help to better understand the earliest pathogenic events in RA.

\section{REFERENCE}

[1] Catrina Al et al. Nat Rev Rheumatol. 2017;13(2):79-86; Klarenbeek PL et al. Ann Rheum Dis. 2012;71(6):1088-93

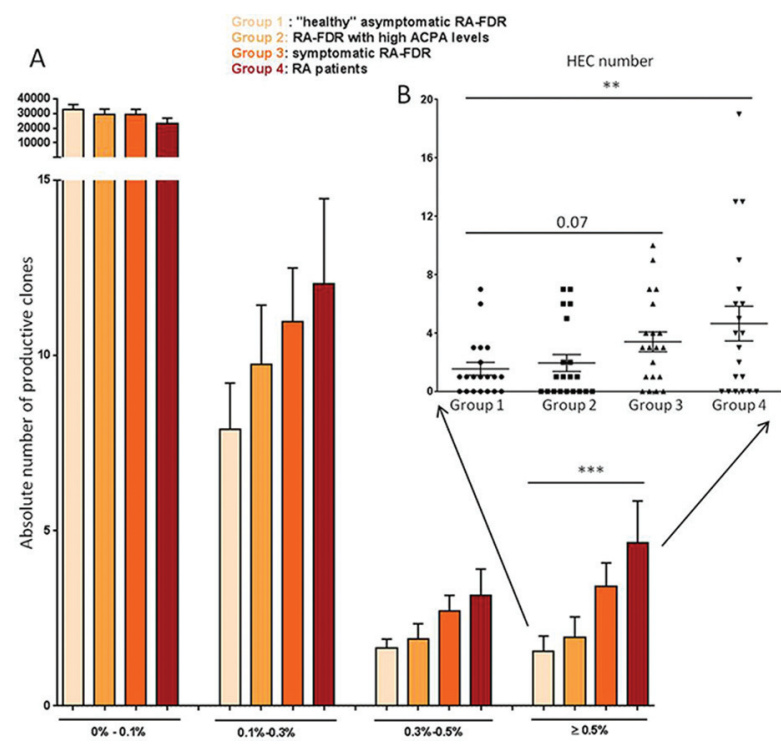

Figure 1. Absolute number of productive TCR clones by clonal size. (A) Bars show mean and standard error of the mean (mixed effect regression model). (B) Each dot represents the HEC number observed for 1 individual (mixed effect regression model).

Disclosure of Interests: Céline Lamacchia: None declared, Zuleika Calderin: None declared, Delphine Courvoisier Grant/research support from: has received an unrestricted grant from MSD for this study, Consultant for: has received consulting fees from BMS, Pfizer, AB2 Bio and Janssen., Paid instructor for: Janssen, Denis Mongin: None declared, Stéphane Buhler: None declared, Gaby Palmer: None declared, Olivia Studer: None declared, Cem Gabay Grant/research support from: Roche, Pfizer, AB2 Bio Ltd, Consultant for: Roche, Pfizer, Lilly, AbbVie, Sanofi, Regeneron, Bristol-Myers Squibb, Novartis, UCB, AB2 Bio Ltd, Debiopharm, Jean Villard: None declared, Axel Finckh Grant/research support from: Bristol-Myers Squibb, Pfizer Inc, Consultant for: AbbVie, A2Bio, Bristol-Myers Squibb, MSD, Roche, Pfizer Inc, and UCB

DOI: 10.1136/annrheumdis-2019-eular.4102

\section{SAT0006 1 T-CELL IMMUNOGLOBULIN AND MUCIN DOMAIN 3 (TIM- 3) IS INCREASED IN ACTIVE RHEUMATOID ARTHRITIS AND ASSOCIATED WITH CLINICAL DISEASE ACTIVITY AND RADIOGRAPHIC PROGRESSION}

Cæcilie Skejø ${ }^{1}$, Morten Aagaard Nielsen ${ }^{1}$, Malene Hvid ${ }^{1,2}$, Aida Solhøj Hansen ${ }^{1}$, Kristian Stengaard-Pedersen ${ }^{2}$, Merete L. Hetland ${ }^{3,4}$, Kim Hørslev-Petersen ${ }^{5}$, Peter Junker ${ }^{6}$, Mikkel Ǿstergaard ${ }^{3,4}$, Stinne Ravn Greisen ${ }^{1}$, Mette Deleuran ${ }^{2,7}$, Bent Deleuran $1,8 .{ }^{1}$ Aarhus University, Biomedicine, Aarhus, Denmark; ${ }^{2}$ Aarhus University, Clinical Medicine, Aarhus, Denmark, ${ }^{3}$ Rigshospitalet, Center for Rheumatology and Spine Diseases, Glostrup, Copenhagen, Denmark; ${ }^{4}$ University of Copenhagen, Clinical Medicine, Copenhagen, Denmark; ${ }^{5}$ University Hospital of Southern Denmark, Danish Hospital for Rheumatic Diseases, Odense, Denmark; ${ }^{6}$ Odense University Hospital, Rheumatology, Odensen, Denmark; ${ }^{7}$ Aarhus University Hospital, Dermato-Venerology, Aarhus, Denmark; ${ }^{8}$ Aarhus University Hospital, Rheumatology, Aarhus, Denmark

Background: Co-inhibitory receptors are important for the regulation of inflammation in autoimmune diseases. Among these, T-cell Immunoglobulin and mucin domain-3 (Tim-3) has recently gained attention, as it is expressed on exhausted T cells co-expressing PD-1 (1).

Objectives: To investigate Tim-3's role in rheumatoid arthritis (RA)

Methods: Early RA (eRA) patients were randomized to conventional methotrexate (MTX) treatment + placebo or MTX + adalimumab (ADA) (2). Plasma were analysed by ELISA at baseline $(n=98)$ and after 3 and 12 months of treatment. Clinical follow up including 28-joint Disease Activity Score with CRP (DAS28CRP) and Total Sharp Score (TSS) were available. Intrasubject differences in sTim-3 between baseline and 3 months were assessed by parametric paired $t$ tests and compared with plasma from HV $(n=44)$ by parametric unpaired $t$ tests. Spearman correlation and Mann-Whitney test were used to investigate relations between sTim-3 and clinical follow up. From chronic RA (cRA) patients $(n=17)$ plasma and synovial fluid were analysed by ELISA and peripheral blood mononuclear cells (PBMC) and synovial fluid mononuclear cells (SFMC) 
$(n=8)$ were analysed by flow cytometry. Intrasubject differences were assessed by paired parametric $t$ tests, and comparison with PBMC from HV $(n=6)$ by unpaired parametric $t$ test. Parametric data are reported as mean differences (MD) $[95 \% \mathrm{Cl}] . \quad \mathrm{P}$ values $<0.05$ were considered significant.

Results: Among memory prone $\mathrm{T}$ cells $\left(\mathrm{CD}^{+} \mathrm{CD}^{+} \mathrm{CD}^{+} 5 \mathrm{RO}^{+}\right)$in $\mathrm{SFMC}$, the percentage of $\mathrm{Tim}^{+} 3^{+}$cells were increased compared with similar gated PBMC from patients (MD 17.4\%, [10.7;24.1], $\mathrm{p}<0.005)$ and HV (MD $12.9 \%$, [4.1;21.8], $\mathrm{p}=0.007)$. In the joint, more of these $\mathrm{Tim}^{+} 3^{+}$cells coexpressed PD-1 compared with similar gated PBMC (MD 42.8\%, [27.8;57.9], $\mathrm{p}<0.005$ ) (Figure 1). On average, sTim-3 plasma levels were higher in eRA compared with HV (MD $4.6 \mathrm{ng} / \mathrm{ml}$, [3.3;5.9], $\mathrm{p}<0.005$ ) (Figure 2). In eRA, baseline sTim-3 levels correlated with DAS28CRP ( $r h o=0.28, p=0.005$ ). eRA patients with TSS progression within 24 months of treatment decreased more in plasma sTim-3 during 3 months of treatment compared with patients without TSS progression (median ${ }^{\text {+progression: - }}$ $1.4 \mathrm{ng} / \mathrm{ml}$, median-progression: $-0.5 \mathrm{ng} / \mathrm{ml}(\mathrm{U}=849.5), \mathrm{p}=0.048)$. The decrease in plasma sTim-3 was not influenced by treatment (median ${ }^{\text {MTX+Placebo:-0.9 }}$ $\mathrm{ng} / \mathrm{ml}$, median MTX+ADA: $-1.2 \mathrm{ng} / \mathrm{ml}(\mathrm{U}=1015), \mathrm{p}=0.4)$. In SF, sTim-3 levels were increased compared with plasma (MD $37.4 \mathrm{ng} / \mathrm{ml}$, [26.3;48.4], $\mathrm{p}<0.0001)$.

Conclusion: Tim-3 expression is upregulated in memory prone $\mathrm{T}$ cells in RA joints and the majority co-express PD-1. Levels of sTim-3 are increased in SF. In eRA, baseline sTim-3 plasma levels are elevated and correlate with DAS28CRP. Decrease of sTim-3 during treatment associates with future radiographic progression. We suggest, that Tim-3 expression and STim-3 plasma and SF levels reflect ongoing immune response, thus immune regulation in RA. These data indicate that maintenance of sTim-3 plasma levels during treatment is favourable, consistent with Tim-3 being a co-inhibitory receptor.

\section{REFERENCE}

[1] Ana C. et al. Immunity 2016;44:989-1004, 2 Hørslev-Petersen K, et al. Ann Rheum Dis 2014;73:654-661.
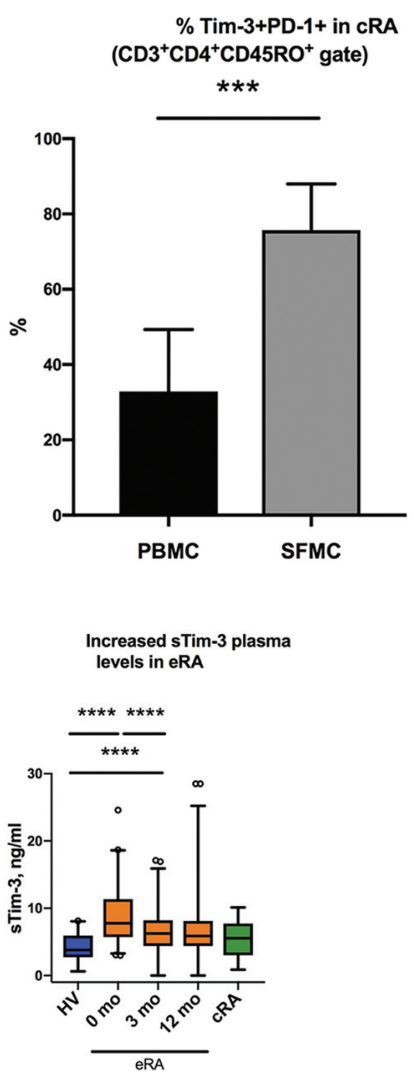

Disclosure of Interests: Cæcilie Skejø: None declared, Morten Aagaard Nielsen: None declared, Malene Hvid: None declared, Aida Solhøj Hansen: None declared, Kristian Stengaard-Pedersen: None declared, Merete L. Hetland Grant/research support from: BMS, MSD, AbbVie, Roche, Novartis, Biogen, Pfizer, Consultant for: Eli Lilly, Speakers bureau: Orion Pharma, Biogen, Pfizer, CellTrion, Merck, Samsung Bioepis, Kim Hørslev-
Petersen: None declared, Peter Junker: None declared, Mikkel Ǿstergaard Grant/research support from: Abbvie, Celgene, Centocor, Merck, Novartis, Consultant for: Abbvie, BMS, Boehringer-Ingelheim, Celgene, Eli Lilly, Hospira, Janssen, Merck, Novartis, Novo, Orion, Pfizer, Regeneron, Roche, and UCB, Speakers bureau: Abbvie, BMS, Boehringer-Ingelheim, Celgene, Eli Lilly, Hospira, Janssen, Merck, Novartis, Novo, Orion, Pfizer, Regeneron, Roche, and UCB, Stinne Ravn Greisen: None declared, Mette Deleuran: None declared, Bent Deleuran: None declared

DOI: 10.1136/annrheumdis-2019-eular.4614

\section{SAT0007 THE SUPPRESSIVE ACTIVITY OF PERIPHERAL BLOOD TREG REPRESENTS IMMUNOLOGICAL REMISSION IN RHEUMATOID ARTHRITIS PATIENTS}

Korawit Kanjana ${ }^{1}$, Parawee Chevaisrakul ${ }^{2}$, Ponpan Matangkasombut ${ }^{3}$, Karan Paisooksantivatana ${ }^{1}$, Putthapoom Lumjiaktase ${ }^{1} .{ }^{1}$ Faculty of Medicine, Ramathibodi Hospital, Mahidol Universitiy, Department of Pathology, Bangkok, Thailand; '² Faculty of Medicine, Ramathibodi Hospital, Mahidol Universitiy, Division of Allergy Immunology and Rheumatology, Department of Medicine, Bangkok, Thailand; ${ }^{3}$ Faculty of Science, Mahidol University, Department of Microbiology, Bangkok, Thailand

Background: Rheumatoid arthritis (RA) patients with sustained remission may have relapsed disease after DMARDs tapering. Many predictors such as multibiomarker disease activity, ultrasound and MRI for detecting subclinical synovitis have some role to be prognostic tools. However, their values are limit. ${ }^{1,2}$ The number of Foxp3+ Treg may indicate immunological status in some situation, but is controversial. ${ }^{3}$ The Treg function may represent the different stages of RA

Objectives: This study aimed to determine the suppressive activity of Foxp3+ Treg from peripheral blood (PB) of RA patients with clinical remission compare with active RA

Methods: In this cross-sectional study, blood samples were collected from RA patients with sustained clinical remission for at least 6 months and from active RA patients. The Treg and autologous conventional $T$ cell were isolated from PB of the patients by using FACS sorting. Then the isolated cells were evaluated suppressive activity by co-culture suppression assay.

Results: The Treg of patients with sustained clinical remission (for more than six months) showed higher suppressive activity compared to Treg from active RA patients $[57.24 \%$ versus $23.67 \%, p<0.0001,95 \% \mathrm{Cl}$; 20.88-44.01(showed in figure 1A)]. Moreover, the suppressive activity correlated with the degree of disease activity. When we analyzed in patients with DAS28 score < 2.6 (remission), >2.6-3.2 (low DAS), >3.2-5.1 (moderate DAS) and $>5.1$ (high DAS), the suppressive activity of Treg dependently decreased to the degree of disease activity $[57.97 \%$, $39.15 \%, 23.01 \%$, and $17.07 \%$, respectively (showed in figure 1B)].

Conclusion: This suppressive activity of Treg may indicate immunological remission in RA patients with clinical remission, especially in patients who candidate for DMARDs reduction.

\section{REFERENCES}

[1] Schett G, Emery P, Tanaka Y, et al. Tapering biologic and conventional DMARD therapy in rheumatoid arthritis: current evidence and future directions. Annals of the Rheumatic Diseases. 2016;75(8):1428

[2] Hirata S, Dirven L, Shen Y, et al. A multi-biomarker score measures rheumatoid arthritis disease activity in the BeSt study. Rheumatology. 2013;52 (7):1202-1207.

[3] Kleinewietfeld M, Hafler DA. The plasticity of human Treg and Th17 cells and its role in autoimmunity. Seminars in Immunology. 2013;25(4):305-12.

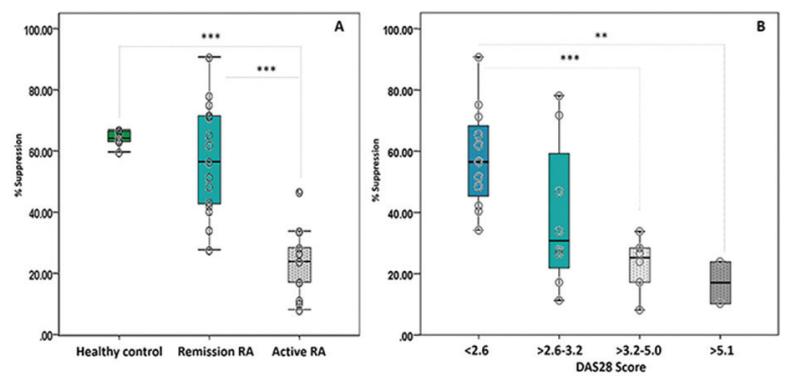

Figure 1. Suppressive activity of Treg in different stages of RA patients. The suppressive activity of Treg was measured by 3 days co-culture suppression assay. (A) Suppressive activity of Treg in healthy control $(n=7)$, clinical remission $(n=14)$ and active RA $(n=13)$. $(B)$ Suppressive activity of Treg in patients with various DAS28 score: DAS28 $<2.6$ (remission), 